\title{
Evaluation of the VKORC 1 and CYP2C9 Gene Polymorphisms and Their Effects on the Emergency Complications in the Patients Using Warfarin
}

\author{
Oğuz Yardım', Emine Emektar², Yunsur Çevik², Şeref Kerem Çorbacıoğlu², Ali Ekber Karabulut ${ }^{2}$ \\ ${ }^{1}$ Clinic of Emergency Medicine, Bayburt State Hospital, Bayburt, Turkey \\ ${ }^{2}$ Clinic of Emergency Medicine, Keçiören Training and Research Hospital, Ankara, Turkey
}

\begin{abstract}
Aim: We aimed to evaluate the effects of genetic polymorphisms on the frequency of application to the emergency service and on the complications with use of warfarin in this study.

Materials and Methods: Seventy patients were included in the study. Two groups were composed: one group of 40 patients who used warfarin and with international normalized ratios (INRs) $\geq 3.5 \mathrm{IU}$ and a second group of 30 control group patients with normal INR levels. Blood samples were examined through the warfarin dosage sensitivity test.

Results: VKORC 1 heterozygote type AG was the most frequently seen allele in 17 of the haplotype patients (42.5\%), in 12 of the control group patients (40\%), in 21 of the CYP2C9* $1 /{ }^{*} 1$ patients $(52.5 \%)$, and in 17 of the CYP2C ${ }^{*} 1 /{ }^{*} 1$ control group patients. No statistically significant difference was identified between the groups $(p>0.05)$. No statistically significant relationship was established as regards the frequency of emergency service visits and bleeding complications with CYP2C9 and VKORC 1 genes.
\end{abstract}

Conclusion: The most common haplotypes VKORC 1 heterozygote type AG and CYP2C ${ }^{*} 1 /{ }^{*} 1$. No relationship was identified between INR levels and VKORC 1 and CYP2C9 haplotypes. These genes have no effect on bleeding and frequent applications of emergency service.

Keywords: Warfarin, gene polymorphism, emergency service, VKORC 1, CYP2C9

\section{Introduction}

Warfarin is a most commonly drug used for the prophylaxis and treatment of venous and arterial thromboembolism. It is now known that genetic factors also play a part in the effect mechanism of warfarin (1). So far, nearly 30 genes have been reported concerning the pharmacokinetics of warfarin. Cytochrome P450 2 C9 (CYP2C9), vitamin $\mathrm{K}$ epoxide reductase complex subunit 1 gene (VKORC1) genes, and their polymorphisms are the ones that have the closest relationship with warfarin (2-4). VKORC1 is a gene and its polymorphism belonging to vitamin $\mathrm{K}$ epoxide reductase enzyme enabling vitamin $\mathrm{K}$ to be formed from reduced vitamin $\mathrm{K}$ epoxide. It has recently been reported that there are a lack of a resistance to warfarin (2), whereas the most common mutations that affect the dosage regulation of warfarin in VKORC 1 genotypes are 1173, 3730, and -1639 single nucleotide polymorphisms (5-8). Another important genetic factor is CYP2C9, a liver enzyme that plays a role in the oxidative metabolism of many other drugs as well as warfarin, and a series of gene polymorphisms were identified in the CYP2C9 gene area $(3,4)$. It has been demonstrated that these polymorphisms lead to difficulty in achieving a stable dosage in patients using warfarin, a decrease in the dosage requirement for warfarin, and a high risk of bleeding at an earlier period of drug use (8). The American Food and Drug Administration recommended that the starting dosage of warfarin should be regulated in accordance with the CYP2C9 and VKORC1 genotypes (5). This study aims to evaluate whether the patients who applied to the emergency unit with supratherapeutic international normalized ratio (INR) levels after using warfarin were different as regards CYP2C9 and VKORC1 genetic polymorphisms than the control group patients with therapeutic INR levels. I addition, this study attempts to reveal the effects of CYP2C9 and VKORC1 genetic polymorphisms on warfarin dosages, the frequency of application to the emergency unit, and the complications that develop due to use of warfarin.

Correspondence to: Emine Emektar e-mail: emineakinci@yahoo.com 


\section{Materials and Methods}

\section{Study design}

The study was a prospective clinical study. After obtaining the approval of the local ethical board, we conducted the study at the Emergency Service of Keçiören Training and Research Hospital between December 15, 2015, and January 1, 2016. Seventy patients who applied to our emergency department for any complaints or for INR control were included the study. Forty patients who had been using warfarin for more than one month and who had INR levels of 3.5 or more were included consecutively in the case group. A control group consisting of 30 patients was included for comparison. The control group was composed of patients who had applied to the emergency service for INR control and who did not have any warfarin overdose (their INR levels were below 3.5). After the patients and their relatives were informed about the situation, the patients for whom confirmation was obtained were taken into the study.

\section{The excluded criteria}

Patients who were under the age of 18 , who had been using warfarin for less than one month, who were using amiodarone, furosemide, heparin, quinolone, metronidazole, omeprazole, sulfonylureas, phenytoin, and tricyclic anti-depressants, and who had an infection were excluded from the study.

\section{Analysis of blood samples}

Three milliliters of blood were taken into tubes with sterile ethylenediamine tetraacetic acid. Isolation of genomic DNA was carried out from the blood samples, following an algorithm, and the distribution of CYP2C9 and VKORC1 alleles between the patients and their relationship with the other variables were examined.

\section{CYP2C9 and VKORC1 alleles}

In our study, we used the PGX-Thrombo Strip Assay (Vienna, Austria) test for laboratory and examined VKORC1-1639 G>A mutant and wild type, CYP2C9 1075 A >C mutant and wild type, and CYP2C9 $430 \mathrm{C}>\mathrm{T}$ mutant and wild type alleles.

The presence of polymorphism in the patients is demonstrated in Table 1.

Table 1. Types of polymorphism

\begin{tabular}{|l|c|c|c|}
\hline & Wild type line & Mutant line & Genotype \\
\hline Normal & Positive & Negative & Normal \\
\hline Heterozygote & Positive & Positive & Heterozygote \\
\hline Homozygote & Negative & Positive & Homozygote mutant \\
\hline
\end{tabular}

\section{VKORC 1 genotypes}

$-1639 \mathrm{G}>\mathrm{A}$, expressed as VKORC $1 \mathrm{AA}$, is made up of homozygote mutant genotypes,

-1639 G > A, expressed as VKORC 1 AG, is made up of heterozygote genotypes, and

$-1639 \mathrm{G}>\mathrm{A}$, expressed as VKORC $1 \mathrm{GG}$, is made up of homozygote normal (wild) genotypes.

\section{CYP2C9 genotypes}

CYP2C9 alleles formed through the mutations of $430 \mathrm{C}>\mathrm{T}$ and $1075 \mathrm{~A}>\mathrm{C}$ are shown in Figure 1 as *1 (wild type), *2 and *3. Homozygotes and heterozygotes are shown as ${ }^{*} 1 /{ }^{*} 1,{ }^{*} 1 /{ }^{*} 2,{ }^{*} 1 /{ }^{*} 3,{ }^{*} 2 /{ }^{*} 2$, and $* 2 * 3$.

\section{Statistical analysis}

The statistical analysis of the study was carried out with the IBM Statistical Package for the Social Sciences (IBM SPSS Statistics, Armonk, NY, USA) version 20.0 package program. In order to evaluate the compatibility of the distribution of alleles and haplotypes with the normal distribution, the Shapiro-Wilk test was employed. For the data that were compatible with the normal distribution, Student t-test was used. For the data that were not compatible, the Mann-Whitney $U$ test was utilized. Descriptive statistics were shown in the form of mean \pm standard deviation or median (minimum to maximum) for interrupted and continuous numeric variables. Categorical variables were shown in the form of case number and percentage (\%). Pearson's X2 test was used for the evaluation of categorical variables. Logistic regression analysis was conducted to compare each polymorphism and the average warfarine dosage of the patients.

\section{Results}

Seventy patients who aged 18-80 were taken into our study. The demographic features of the patients are shown in Table 2.

Vitamin $\mathrm{K}$ epoxide reductase complex subunit 1 heterozygote type AG haplotype was the most commonly seen allele identified in 17 patients in the patient group (42.5\%) and in 12 patients in the control group (40\%), whereas CYP2C9 $* 1 / * 1$ was the most commonly seen allele identified in 21 patients in the patient group (52.5\%) and CYP2C9 $* 1 /{ }^{*} 1$ was the most commonly seen allele found in 17 patients in the control group (56.7\%). No statistical difference was detected between the groups ( $p>0.05$ ) (Table 3).

In terms of INR levels of the patient group, no statistical difference was found between VKORC 1 and CYP2C9 haplotypes $(p=0.305$ and $p=0.088$, respectively), whereas a significant difference was found on weekly warfarin dosages of VKORC 1 homozygote normal GG and CYP2C9 $* 1 /{ }^{*} 1$ homozygote normal (wild) carriers $(p=0.02$ and $\mathrm{p}=0.034$, respectively) (Table 4 ).

$1075 \mathrm{~A}>\mathrm{C}$
$430 \mathrm{C}>\mathrm{T}$
$1075 \mathrm{~A}>\mathrm{C}$
$430 \mathrm{C}>\mathrm{T}$
$\begin{aligned} & \text { mutant } \\ & \text { wild type } \\ & \text { wild type }\end{aligned}$

Figure 1 . CYP2C9 genotypes 
Table 2. Clinical characteristics of study

\begin{tabular}{|c|c|c|c|}
\hline & Case, n (\%) & Control, n (\%) & $\mathbf{p}$ \\
\hline \multicolumn{4}{|l|}{ Sex, n (\%) } \\
\hline Female & $31(77.5)$ & $22(73.3)$ & 0.687 \\
\hline Male & $9(22.5)$ & $8(26.7)$ & \\
\hline Age median (IQR 25-75) & $76(50-80)$ & $68.5(50-80)$ & 0.012 \\
\hline \multicolumn{4}{|l|}{ Comorbidity, n (\%) } \\
\hline Diabetes mellitus & $8(20)$ & $10(33.3)$ & 0.207 \\
\hline Hypertension & $26(65)$ & $22(73.3)$ & 0.457 \\
\hline Coronary artery disease & $16(40)$ & $14(46.7)$ & 0.577 \\
\hline Other & $19(47.5)$ & $10(33.3)$ & 0.234 \\
\hline \multicolumn{4}{|l|}{$\begin{array}{l}\text { Indication for warfarin } \\
\text { therapy, } \mathrm{n}(\%)\end{array}$} \\
\hline Atrial fibrillation & $17(42.5)$ & $9(30)$ & 0.010 \\
\hline Heart valve replacement & $9(22.5)$ & $17(56.7)$ & \\
\hline Thromboembolism & $14(35)$ & $4(13.3)$ & \\
\hline Bleeding, n (\%) & $17(42.5)$ & $1(3.3)$ & - \\
\hline \multicolumn{4}{|l|}{ Bleeding field, n (\%) } \\
\hline Gastrointestinal bleeding & $5(12.5)$ & & \\
\hline Hematuria & $2(5)$ & & - \\
\hline Epistaxis & $2(5)$ & $1(3.3)$ & \\
\hline Skin & $2(5)$ & & \\
\hline Hemoptysis & $1(2.5)$ & & \\
\hline Other & $2(5)$ & & \\
\hline \multicolumn{4}{|l|}{$\begin{array}{l}\text { The number of overdose } \\
\text { in the last year (\%) }\end{array}$} \\
\hline 0 & - & $19(63.3)$ & \\
\hline 1 time & $25(62.5)$ & $6(20)$ & \\
\hline 2 times & $11(27.5)$ & $4(13.3)$ & \\
\hline 3 times and higher & $4(4)$ & $1(3.3)$ & $<0.05$ \\
\hline IQR: interquartile range & & & \\
\hline
\end{tabular}

Table 3. Distribution of CYP2C9 and VKORC1 genotypes

\begin{tabular}{|l|c|c|c|c|}
\hline \multicolumn{2}{|l|}{ Genotype } & $\begin{array}{c}\text { Frequency, } \\
\text { n (\%) case }\end{array}$ & $\begin{array}{c}\text { Frequency, } \\
\text { n (\%) control }\end{array}$ & p \\
\hline \multirow{2}{*}{ VKORC 1 } & AA & $14(35)$ & $9(30)$ & \\
\cline { 2 - 5 } & AG & $17(42.5)$ & $12(40)$ & \\
\cline { 2 - 5 } & GG & $9(22.5)$ & $9(30)$ & 0.53 \\
\hline \multirow{2}{*}{ CYP2C9 } & $* 1 /{ }^{*} 1$ & $21(52.5)$ & $17(56.7)$ & \\
\cline { 2 - 5 } & Others & $19(47.5)$ & $13(53.7)$ & 0.630 \\
\hline
\end{tabular}

VKORC1: vitamin K epoxide reductase complex subunit 1 gene; CYP2C9: cytochrome P450 2C9; Others: CYP2C9 *1 / ${ }^{*} 2,{ }^{*} 1 /{ }^{*} 3, * 2 /{ }^{*} 2,{ }^{*} 2 /{ }^{*} 3,{ }^{*} 3$ / *3 haplotypes
Table 4. The relationship with the weekly warfarin dose and INR of genotypes in case groups

\begin{tabular}{|c|c|c|c|c|}
\hline \multirow[b]{2}{*}{ Genotypes } & \multicolumn{2}{|l|}{$\begin{array}{l}\text { INR median } \\
\text { (min-max) }\end{array}$} & \multicolumn{2}{|c|}{$\begin{array}{l}\text { Weekly warfarin dose median } \\
\text { (min-max) }\end{array}$} \\
\hline & Case & $\mathbf{p}$ & Case & $\mathbf{p}$ \\
\hline \multicolumn{5}{|l|}{ VKORC 1} \\
\hline$A A$ & $8.36(3.83-15.63)$ & 0.3 & $26.2(17.5-35)$ & 0.02 \\
\hline AG & $7.76(4.03-15)$ & & $30(13.75-35) 35(17.5-45)$ & \\
\hline GG & $4.82(3.62-13.48)$ & & & \\
\hline \multicolumn{5}{|l|}{ CYP2C9 } \\
\hline${ }^{*} 1 /{ }^{* 1}$ & $8.77(3.62-15)$ & 0.08 & $35(17.5-40)$ & \\
\hline Others & $2.32(3.83-15.63)$ & & $27,5(17.5-40)$ & 0.03 \\
\hline \multicolumn{5}{|c|}{$\begin{array}{l}\text { VKORC1: vitamin K epoxide reductase complex subunit } 1 \text { gene; CYP2C9: } \\
\text { cytochrome P450 2C9; INR: international normalized ratio; Others: CYP2C9 } \\
{ }^{*} 1 /{ }^{*} 2,{ }^{*} 1 /{ }^{*} 3,{ }^{*} 2 /{ }^{*} 2,{ }^{*} 2 /{ }^{*} 3,{ }^{*} 3 /{ }^{*} 3 \text { haplotypes }\end{array}$} \\
\hline
\end{tabular}

When the number of visits by the patients to the emergency service was evaluated, it was shown that patients from the case group had more frequest admission to emergency service. $(p=0.001)$ (Table 2). In terms of the frequency of visits to the emergency service, no statistical difference was found either for CYP2C9 or for VKORC 1 (Table 5).

Gastrointestinal bleeding was the most frequently observed form of bleeding. Complications due to bleeding were present in patient group, whereas it was observed in 17 patients in the case group (42.5\%). No statistical difference was established between CYP2C9 and VKORC 1 haplotypes in terms of complications due to bleeding ( $p>0.05$ and $p=0.576$, respectively) (Table 6).

Finally, when we evaluated to association between the average warfarin dosage of the patients and the gene polymorphism by logistic regression analysis, we did not find any correlation $(p=0.2)$.

\section{Discussion}

In our study, in which we evaluated the effect of CYP2C9, VKORC1 genetic polymorphisms, warfarin dosages and complications, no difference was observed between the patient and control groups in terms of haplotypes in warfarin-using patients. Moreover, it was seen that carriers of VKORC 1 homozygote normal GG and CYP2C9 $* 1 / * 1$ homozygote normal (wild) had a higher dosage requirement for warfarin compared with the other genotypes. No relationship was found between INR levels and VKORC 1 and CYP2C9 haplotypes. VKORC 1 and CYP2C9 had no effect on bleeding and frequent visits to the emergency services.

There are two points that require particular attention in patients using warfarin during the process of treatment: (1) specifying an effective and safe stable dosage in the first months of the treatment, during which bleeding is particularly frequent, and (2) regulating this continual dosage in accordance with any change in the diet, weight, any new disease or additional drugs. Recent studies have revealed that genetic factors should also evaluate, as well as these factors (9). So, far, nearly 30 genes have been reported in association with warfarin pharmacogenetics. CYP2C9 and VKORC1 genes are the genes with the highest association with warfarin (2-4). 
Table 5. The relationship between recurrent admission due to warfarin overdose of VKORC1 and CYP2C9 genotypes

\begin{tabular}{|c|c|c|c|c|c|c|c|}
\hline \multirow[b]{2}{*}{ Recurrent admission } & \multicolumn{3}{|c|}{ VKORC 1} & \multirow[b]{2}{*}{$\mathbf{p}$} & \multicolumn{2}{|c|}{ CYP2C9 } & \multirow[b]{2}{*}{$\mathbf{p}$} \\
\hline & AA & AG & GG & & $* 1 / * 1$ & Others & \\
\hline None & $6(8.6 \%)$ & $6(8.6 \%)$ & $7(10 \%)$ & & $12(17.1 \%)$ & $7(10 \%)$ & \\
\hline 1 time & $8(11.4 \%)$ & $14(20 \%)$ & $9(12.9 \%)$ & 0.268 & $17(24.3 \%)$ & $14(20 \%)$ & 0.52 \\
\hline 2 and more & $9(12.9 \%)$ & $9(12.9 \%)$ & $2(2.9 \%)$ & & $19(12.9 \%)$ & $11(15.7 \%)$ & \\
\hline Total & $23(32.9 \%)$ & $29(41.4 \%)$ & $18(25.7 \%)$ & & $38(54.3 \%)$ & $32(45.7 \%)$ & \\
\hline
\end{tabular}

VKORC1: vitamin K epoxide reductase complex subunit 1 gene; CYP2C9: cytochrome P450 2C9; Others: CYP2C9 $* 1 / * 2, * 1 / * 3, * 2 / * 2, * 2 / * 3, * 3 / * 3$ haplotypes

Table 6. The relationship between bleeding complications of VKORC1 and CYP2C9 genotypes

\begin{tabular}{|c|c|c|c|c|c|c|c|}
\hline \multirow[b]{2}{*}{ Bleeding } & \multicolumn{3}{|c|}{ VKORC 1} & \multirow[b]{2}{*}{$\mathbf{p}$} & \multicolumn{2}{|c|}{ CYP2C9 } & \multirow[b]{2}{*}{$\mathbf{p}$} \\
\hline & AA & AG & GG & & $* 1 / * 1$ & Others & \\
\hline Yes & $6(8.6 \%)$ & $9(12.9 \%)$ & $3(4.3 \%)$ & & 10 (14.3\%) & $8(11.4 \%)$ & \\
\hline No & $17(24.3 \%)$ & 20 (28.6\%) & 15 (21.4\%) & 0.57 & $28(40 \%)$ & $24(34.3 \%)$ & $>0.05$ \\
\hline Total & 23 (32.9\%) & 29 (41.4\%) & $18(25.7 \%)$ & & 38 (54.3\%) & 32 (45.7\%) & \\
\hline
\end{tabular}

VKORC1: vitamin K epoxide reductase complex subunit 1 gene; CYP2C9: cytochrome P4502C9; Others: CYP2C9 $* 1 / * 2,{ }^{*} 1 / * 3,{ }^{*} 2 / * 2,{ }^{*} 2 / * 3,{ }^{*} 3 / * 3$ haplotypes

The prevalence of CYP2C9 and VKORC1 alleles varies with ethnic groups. In our study, we found that CYP2C9*1/*1 haplotype was at a rate of $54.3 \%$, and we identified it more commonly than we identified the other five haplotypes. While CYP2C9*5 and *6 alleles were more prevalent in African society, the prevalence of CYP2C9 *2 and CYP2C9 * 3 was found to be lower among Chinese and Malaysian people (10). There is considerable research in the literature demonstrating that genetic polymorphisms of CYP2C9 $* 2$ and CYP2C $9 * 3$ reduce the dosage requirement of warfarin (11-13). In Sanderson's study, CYP2C9 *2 genetic polymorphism reduced the dosage requirement by $17 \%$, while CYP 2 C9*3 genetic polymorphism reduced the dosage requirement by $37 \%$ (11). Similarly in the study by Lindh et al. (12) CYP2C $9 * 1 / * 1$ carriers had a reduced dosage requirement compared with the other carriers (12). Also in our study, when CYP2C $* * 1 /{ }^{*} 1$ (homozygote normal) carriers were compared with the other carriers, no significant difference was observed as regards warfarin dosage requirement, as has been demonstrated in the literature.

The VKORC 1 allele most frequently seen in our study was heterozygote type AG haplotype, but in VKORC 1 genotypes, the most common mutation that affected the dosage regulation were 1173, 3730, and -1639 single nucleotide polymorphisms (5-7). Among Japanese people, while the ratio of VKORC1 -1639 G/G homozygote normal was extremely high (79.4\%), the ratio of $-1639 \mathrm{~A} / \mathrm{A}$ homozygote mutant was negligibly low (0.8\%) (6). In a study conducted by Gan et al. (14) revealed that VKORC 1 genetic polymorphism was quite common among Chinese and Malaysian people, but it had a low ratio among Indian people. These polymorphisms, which were identified in the VKORC 1 gene, could change the dosage requirement for warfarin. Özer et al. (13), stated that VKORC1 -1639 G > A polymorphisms had the most important role. Similarly, in a study by Gan et al. demonstrated that patients with the GG genotype in the gene area of VKORC1 $-1639 \mathrm{G}>\mathrm{A}$ had the highest dosage requirement for warfarin, patients with the AG genotype had a moderate dosage requirement for warfarin, and patients with the AA genotype had the lowest dosage requirement for warfarin (14).
Also in our study, a statistically significant difference was detected between haplotypes as regards warfarin dosage requirement both in the case group, in which the effect of overdose was seen at the time of the application, and in the control group, in which the ideal dosage was supposedly reached and no effect of overdose was seen. It was determined that while a higher dosage of warfarin was needed for VKORC 1 GG carriers, a lower dosage of warfarin was required for VKORC 1 AA carriers.

Warfarin is used in different indications and in increasing amounts today increases the likelihood of its side effects as well as its benefits (15). The most serious side effect resulting from an overdose of warfarin treatment is bleeding. When we evaluated the role of CYP2C9 and VKORC1 genetic polymorphisms in frequent applications to the emergency service and bleeding complications, we were unable to detect any effects of CYP2C9 and VKORC 1 haplotypes in terms of bleeding and frequent applications to the emergency service. We think that this may stem from the low number of the patients in our study.

\section{Study limitations}

Our study is a single-center study. The number of cases is low. Another limitation of our study is the fact that there were age differences between the patients in the patient and control groups. Apart from genetic factors, there are a number of factors that have an effect on the pharmacogenetics of warfarin. Among them, age is the leading factor. In our study, the difference in ages between the groups, as well as genetic polymorphism, might have had an effect on the weekly warfarin dosage that the patients used.

\section{Conclusion}

In this study, we could not clarify the effects of genetic polymorphisms on warfarin overdose and associated complications in emergency services. This may have to do with the low number of patients in our study. Further studies that include more patients and through 
which better results could be obtained with respect to cost and efficiency are required.

Ethics Committee Approval: Ethics committee approval was received for this study from the ethics committee of Keçiören Training and Research Hospital.

Informed Consent: Written informed consent was obtained from patients and patients' parents who participated in this study.

Peer-review: Externally peer-reviewed.

Conflict of Interest: No conflict of interest was declared by the authors.

Financial Disclosure: The authors declared that this study has received no financial support.

\section{References}

1. Goldstein JA. Clinical Relevance of Genetic Polymorphisms in Human CYP'C Subfamily. Br J Clin Pharmacol 2001; 52: 349-55. [CrossRef]

2. Rost $\mathrm{S}$, Fregin $\mathrm{A}$, Ivaskevicius $\mathrm{V}$, Conzelmann $\mathrm{E}$, Hörtnagel $\mathrm{K}$, Pelz HJ, et al. Mutations in VKORC1 cause warfarin resistance and multiple coagulation factor deficiency Type 2. Nature 2004; 427: 537-41. [CrossRef]

3. Rettie AE, Korzekwa KR, Kunze KL, Lawrence RF, Eddy AC, Aoyama T, et al. Hydroxylation of Warfarin by Human CDNA-expressed Cytochrome P450: A Role for P4502C9 in The Etiology of (S)- warfarin Drug Interactions. Chem Res Toxicol 1992; 5: 54-9. [CrossRef]

4. Stubbins MJ, Harries LW, Smith G, Tarbit MH, Wolf CR. Genetic Analysis of The Human Cytchrome P450 CYP2C9 Locus. Pharmacogenetics 1996; 6: 429-39. [CrossRef]

5. You M, Kenji N, Yoshiki S. Clinical Significance of Combined CYP2C9 and VKORC1 Genotypes in Japanese Patients Requiring Warfarin. Int Heart J 2011; 52: 44-9. [CrossRef]
6. Yang L, GeW, Yu F, Zhu H. Impact of VKORC1 gene polymorphism on inter individual and inter ethnic warfarin dosage requirement- $\mathrm{A}$ systematic review and meta analysis. Thrombosis Research 2010; 125: 159-66. [CrossRef]

7. Wilke RA, Berg RL, Vidaillet HJ, Caldwell MD, Burmester JK, Hillman MA. Impact of age, CYP2C9 genotype and concomitant medication on the rate of rise for prothrombin time during the first 30 days of warfarin therapy. Clin Med Res 2005; 3: 207-13. [CrossRef]

8. Aithal GP, Day CP, Kesteven PJ, Daly AK. Assosiation of Polymorphisms in The Cytochrome P450 CYP2C9 with warfarin dose requirment and risk of bleeding complications. Lancet 1999; 353: 717-9. [CrossRef]

9. Higashi MK, Veenstra DL, Kondo LM, Wittkowsky AK, Srinouanprachanh $\mathrm{SL}$, Farin FM, et al. Association between CYP2C9 genetic variants and anticoagulation-related outcomes during warfarin therapy. JAMA 2002; 287: 1690-8. [CrossRef]

10. Ngow HA, WanKhairina WMN, Teh LK, Lee WL, Harun R, Ismail R, et al. CYP2C9 polymorphism: prevalence in healthy and warfarin-treated Malay and Chinese in Malaysia. Singapore Med J 2009; 50: 490-3.

11. Sanderson S, Emery J, Higgins J. CYP2C9 gene variants, drug dose, and bleeding risk in warfarin-treated patients: A HuGEnetTM systemic review and meta-analysis. Genet Med 2005; 7: 97-104. [CrossRef]

12. Lindh JD, Holm L, Andersson ML, Rane A. Influence of CYP2C9 genotype on warfarin dose requirements- a systemic review and meta-analysis. Eur J Clin Pharmacol 2009; 65: 365-75. [CrossRef]

13. Özer N, Cam N, Tanyürek B, Özer S, Uyarel H, Öz D, et al. The impact of CYP2C9 and VKORC1 genetic polymorphism and patient characteristics upon warfarin dose requirements in an adult Turkish population. Heart Vessels 2010; 25: 155-62. [CrossRef]

14. Gan GG, Phipps ME, Lee MM, Lu LS, Subramaniam RY, Bee PC, et al. Contribution of VKORC1 and CYP2C9 polymorphisms in the inter ethic variability of warfarin dose in Malaysian populations. Ann Hematol 2010; 90: 635-4. [CrossRef]

15. Flaherty, M, Kissela B, Woo D, Kleindorfer D, Alwell K, Sekar P, et al. The increasing incidence of anticoagulant-associated intracerebral hemorrhage. Neurology 2007; 68: 116-21. [CrossRef] 